\title{
PROXIMITY: LOCALIZATION VS. DistaNCE IN PR NEWS RELEASES
}

By Linda P. Morton and John Warren

Charting the use made of 197 news releases mailed from a Mississippi university to 121 daily and weekly state newspapers tested this question: which results in more use, the proximity of the public relations release source or localization of the facts in the story. The influence of proximity proved to be very slight but localization of stories resulted in relatively higher use. This study compared costs and concludes that localization of public relations news releases may be worth - in the age of wordprocessing computers - the small extra expense.

Public relations practitioners who write news releases are successful only if those releases are published in some form. Yet studies indicate that only $3 \%$ to $5 \%$ of all news releases are published. ${ }^{1}$ In an attempt to get a greater percent of their releases published, many public relations practitioners rely on studies of news elements. Studies of one news element, proximity, have produced conflicting information because it contains two separate components: geographic distance and localization. Geographic distance is the measure of the distance between the source of the news story and the newspaper where the to-publish/notto-publish decision is made. Localization is the presence of a local angle to the story. This combination seems to have confounded research results because the effect of localization has been masked by geographic distance.

Past research on proximity falls into three categories: (1) that which used it to mean both geographic distance and localization, (2) that which used it to mean gengraphic distance, and (3) that which used it to mean lucalization. The relationship between news releases containing "proximity" and publication of the releases has differed depending upon how the researcher interpreted proximity.

Whitlow used proximity to mean both geographic distance and localization and found proximity to be one of four factors accounting for

Linda Morton is an associate professor of journalism at the University of Oklahoma's H.H. Herhert Srhool of Journalism and John Warren is vice president of the research firm of Erdos and Morgan in New York.

Journalism Quarterly Vol. 69, No. 4 Winter 1992 1023-1028 01992 AEIMC 
publication decisions of 36 gatekeepers with two of five types of editors selecting stories primarily on proximity. ${ }^{2}$ Aronoff also used proximity to mean both geographic distance and localization and found it to correlate "most highly with the accept/reject variable."3

Similarly. Clyde and Buckalew considered both geographic distance and localization and found that editors ranked news items having the news elements conflict, proximity and timeliness higher than those without them, and higher than those with the news elements impact or known principals. ${ }^{4}$

Several researchers who isolated geographic distance from localization found it not to be as good a predictor of publication as when the two components were considered together. Luttberg studied a plane crash, a major event for the 75 newspapers located close by. He found that those "papers covering a story on average" were only "two miles closer than those omitting coverage." He concluded that "actual distances (1) each day's events play little role in their (gatekeepers')"... judgment as fo which stories to include in their paper. 5

Martin hypothesized that newspapers closest to a community where an event takes place publish more stories about it, but his findings caused him to note a possible confounding of the proximity element:

The Courier-Journal and Times, though sister publications of the news organization, gave different amounts of space to the contract issue from one another. This somewhat confounds the results, suggesting a factor other than simple organization proximity. ${ }^{6}$

Shoemaker and Mayfield also interpreted proximity as distance and concluded that it "may not serve as a good measure of newsworthiness ...."7

Other studies looked specifically at how localization affected the acceptance of news releases. Abbott and Brassfield defined proximity as "the localness factor" and found it to be "the single most important factor for both television and newspapers in accepting or rejecting a news release." The gatekeeplers in their study preferred news releases which were tailored to the locality and medium. ${ }^{8}$

${ }^{1}$ Bill Baximr, "Oklabona Editors Look for Local Angle in PR Ruleases," Publishers' Auxiliury 7 (Fub. 12, 1979). Nutional Newspaper Association, "Editors Polled on Acceptability of Nuws Ruluasus," Edlitor and Publishers, 30 (Novenibur 19, 1979). Michaul Ryan and Dorothe Owhn, "A Content Analysis of Metropolitan Nuwspaper Coverage of Social Issuns," Journalism Quurterly 53:634-640,671 (Winter 1976).

¿S. Scott Whitlow, "How Male and Fumale Gatekeepers Respond to News Stories of Women," Journulism Quorterly 54:573-579, 6009 (1977), p. 575.

Traig Arouoff, "Predictors of Success in Placing Reluasess in Newspapers," Public Relutions Review 2:43.57 (1976), p. 50, 52.

${ }^{4}$ Roliert W. Clyde aud James K. Buckalew. "Inter-Media Standardization: a Q-Analysis of Nuws Editors," Journalism Quarterly 46:14!)-351 (Sumner 196!).

"Norman R. Luttberg, "Proximity Dors Not Assure Newsworthiness," fournulism Quurterly (i0) $7: 31-7: 32$ (Winter 1983)

tishanuon Rossi Martin, "Proximity of Event as Factor in Selection of News Sourcus." Jrurnulism Quorterly 65:986-989, 1043 (Winter 1988), p. 989.

${ }^{7}$ Pamela J. Shommaker with Elizabuth Kay Mayfinld, "Building a Theory of News Contunt: A Syuthesis of Current Approaches," Journalism Monogmphs 103 (June 1987), p. 11.

"Eric A. Abbotl and Lyn T. Brassfield, "Comparing Decisions on Reluases by TV and Newspaper Gateketpers," Journulism Quarterly 66:853-858 (Winter 1989) 
Several other studies have found a lack of localization or local interest to be a frequent reason that editors cite for rejecting releases. ${ }^{9}$ One by Elfenbein surveyed 170 business editors nationwide to determine their evaluations of news releases. They stressed their need for hometown angles or localized information. Yet the editors in Elfenbein's study reported that most $(95 \%)$ of the releases they received did not refer to "local companies, industries or interests." Consequently these releases were not used. 10

Likewise, Turk found little attempt to localize information. On the contrary, the state agency public information officers in her study gave the "same information news release... to all newspapers, whether there was a specific local angle or not." 11

Hypothesis 1: Placement of general news releases is negatively correlated with the geographic distance between the newspapers and location where the release was issued.

Hypothesis 2: Placement of localized releases is negatively correlated with the geographic distance between the newspapers and location where the release was issued.

Hypothesis 3: Placement of localized releases is greater than that of general releases regardless of geographic distance between the newspapers and location where the release was issued.

The subjects of this study are 197 press releases mailed from the public relations defpartment of a regional Mississippi university during the six-month period from Jume to December 1988. Of the 197 releases, 23 were general in nature, with no attempt to localize their contents. A total of 1,774 copies of these 23 releases was distributed to Mississippi newspapers. The 174 other releases were localized by being partially rewritten for each newspaper to which they were sent.

A localized release was defined as one in a series of releases in which the lead and associated material had been rewritten to be of interest to the specific paper to which it was being sent. For example, a release concerning the awarding of scholarships might contain a list of the recipients. General releases would have a generic lead with the list of recipients in the body of the text. In a localized release, the lead would contain the name or names of individuals residing in the circulation area of the paper to which that release

\footnotetext{
"Garol Ana Honey. "The Utilization of Press Releases by Two Metropolitan Newspapers, "unpublisbed M.S. Thesis, Vandurbilt Luiversity, 1979. John L. Maki, "Editors and Nuws Diructors" Opinious of Publicity Ruleashs Ructived by Wyoming Newspapers and Radio Stations," unpublished M.S. Thesis, University of Wyoming, 1980. Charles Honaker, "News Releasus Revisitud," Puthlic: Relations Journal, 37:25-27 (1981). Purry Jonathan Astaley. "Stitection and Llse of State News by Wetkly Newspapers in Kentucky," Diss. Soutliern Illinois (iniversity, 1ut\$

10Dick Elfenbein. "Busiurss Jourualists Say il It's Not Local, It's Trastued," Editor \& Publisher 19, 32-33 (March 22, 198(i), p. 19)

${ }^{11}$ Judy VanSlyke Turk. "Intormation Sulsidies and Media Content: A Cast Study of Public Retations lufluture: ou the News," Journalism Monogruphs 100 (Dec. 1986).
} 
TABLE 1

Analysis of

Variance of

Usage of

Localized

Releases,

Generalized

Releases,

Geographic

Distance.

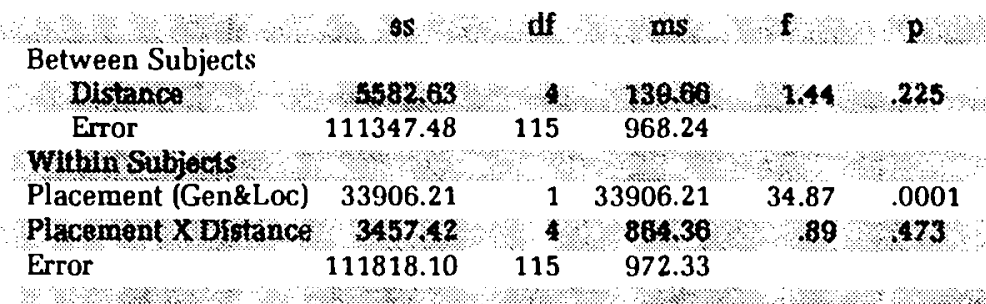

was being sent. Because totally custom-written releases, such as hometowners, might bias the study in favor of the hypotheses, each release used in the study had to contain at least $55 \%$ of text common to the series. Percentages were calculated by measuring the release and the common material. If any paragraph contained information unique to the release, the entire paragraph was considered localized.

The releases were mailed to 121 daily and weekly newspapers in Mississippi. The Commercial Dispatch, a newspaper in Columbus. Mississippi, was excluded from the study because it was within two miles of the university, and therefore, all releases from that source would be considered local. Because geographic distance as well as localization has been found to influence publication, geographic distance was used as a covariate. The actual mileage of each paper from the university was used to test hypotheses one and two with Pearson Correlations. For hypothesis three the distance was coded on a five-point ordinal scale: $1=<50$ miles, $2=50$ to 99 miles, $3=100$ to 149 miles, $4=150$ to 199 miles, $5=>199$ miles. A $2 \times 5$ mixed design MANOVA was used with repeated measures for the percent of general and localized releases placed as the within factor and geographic distance as the between factor. A significance level of .01 was used.

A professional clipping service was used to monitor use of the press releases by the newspapers. A release was considered used if it was published substantially in its original form.

\section{Results}

Of the 1.774 copies of the 23 general releases, $87(5 \%)$ were used by 39 newspapers. Of the newspapers that used general releases, $35 \%$ used $10 \%$ or fewer of the releases. Of the 174 localized releases, $78(45 \%)$ were used. Eighty one newspapers received the localized releases. Of this number, 47 $(58 \%)$ used at least one release, and more than $17 \%$ used every release sent them.

\section{Findings on Hypotheses 1 and 2}

No significant correlation was found between newspapers' acceptance rates for either general or localized releases and geographic distance (r for general releases $=-.1327, p=.074 ; \mathrm{r}$ for localized $=-.1577, p=.043$ ). Although the correlation for distance with localized releases was in the predicted direction and would have been significant if the common significance level of .05 had been used, the small coefficient indicates only a slight relationship. 


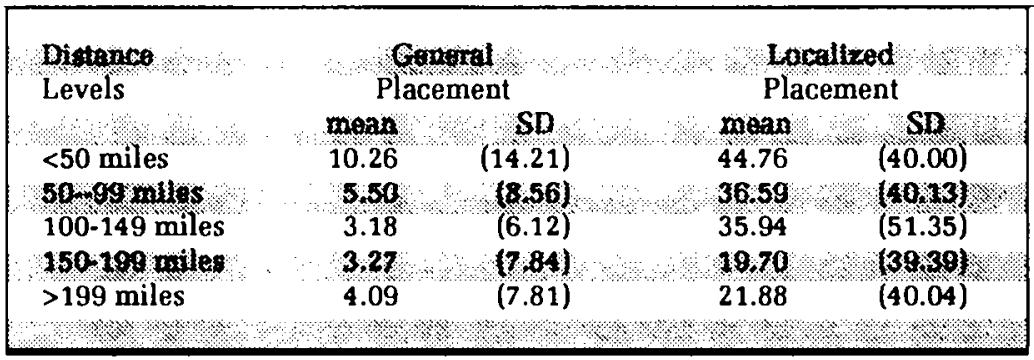

TABLE 2

Mean

Placement of

Generalized

and Localized

Releases

by Distance

Levels

Finding on Hypothesis 3

The usage rates of the general and the localized releases were tested with a 2 X 5 repeated-measures MANOVA with distance as a covariate. Results are shown in Table 1. Localized releases showed a much greater usage rate than general releases.

This study indicates that the positive relationship between proximity Discussion and publication is actually a result of localization. Although there was some evidence that newspapers closer to the source showed a slightly greater disposition toward publishing a general release, this disposition was slight. However, as means in Table 2 indicate, localized releases were significantly more likely to be published than a general release regardless of the recipient newspaper's distance from the source.

This study confirms with controlled, statistical evidence previous research on the positive effects of localization. Although practitioners have for some time acknowledged a vague belief in the advantages of localization, studies like Turk's indicate that they do not localize releases. ${ }^{12}$

Several explanations of this phenomenon suggest themselves. First, the evidence may have been seen as sufficiently weak so that practitioners rejected it. However, this study indicates that the effect is far from mild.

Second, practitioners may have experienced the inertia that manifests itself when a change requires additional work. However, in the present study. the 174 local releases resulted in almost as many publications (78) as the 1,774 copies of the general releases (87). With today's standard use of computerized word-processing equipment, localizing releases is not nearly as much work as in the past. For instance, in timing the difference between production of a generalized release and five localized releases, the difference from composing through copying was only ten minutes or two minutes per localized article. Since mailing and copying costs are the same per release, this time difference at $\$ 10$ per hour equals a total cost difference of only 33.3 rents per localized release. Furthermore, it could easily be argued that preparing and mailing 80 localized releases is less trouble than photocopying and mailing 1,000 copies of general releases.

Third, accountability on the part of public relations professionals has often been defined as number of releases sent out rather than the number

$12 / 1 / n d$. 
placed. However, as public relations matures, the emphasis is shifting from volume to effect. The accept/reject ratio of releases is one criterion upon which campaigns are now being measured. Localization allows the practitioner to improve effects with very little extra effort. For instance, of the releases in this study, less than a quarter ( $m=22.12 \%$ ) of the contents were localized, and $77 \%$ had less than $30 \%$ localized material.

Localizing releases may improve practitioners media relations and improve credibility. Even though research shows that journalists have a better relationship with PR professionals whom they deal with frequently, ${ }^{13}$ it's reasonable to postulate that credibility of a source from which journalists are constantly receiving unusable information decreases. Logically, the converse would apply when releases are localized and, as such, more usable. (This relationship between localizing releases and increasing credibility needs to be studied.)

Fortunately for public-relations practitioners, geographic distance, over which they have little control, seems to have little effort over editors' Iecision-making while localization, which they can use as a tool, seems to be it significant factor.

1:Drunis W. Juffers, "Preformance Expertations as a Measure of Relative Status of Nuws and

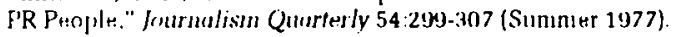

